\title{
Modeling Solvent Enhanced Gravity Drainage from a Single Matrix Block in Fractured Oil Reservoirs
}

\author{
Amin Sharifi Haddad ${ }^{\mathrm{a}, 1}$, S. Hossein Hejazi ${ }^{\mathrm{b}}$, Ian D. Gates ${ }^{\mathrm{b}}$ \\ ${ }^{\text {a }}$ School of Engineering, University of Aberdeen, SCO, UK \\ ${ }^{\mathrm{b}}$ Department of Chemical and Petroleum Engineering \\ Schulich School of Engineering \\ University of Calgary, AB, Canada
}

\section{Abstract}

Solvent based oil recovery is one of the fast growing methods for low emissions-intensity oil recovery from underground resources. In particular, in fractured reservoirs, miscible solvents are injected, and through diffusion and dispersion processes they mix with oil inside the matrix blocks where the oil phase viscosity can be reduced. Consequently, gravity drives the solvent-oil mixture from matrix into fractures, and drained oil is then produced from fracture network. In low permeability matrix blocks or reservoirs with viscous oil, diffusion and convection controls the rate of mass transfer between oil in matrix blocks and solvent in fractures. This study provides a novel semi-analytical solutions that can accurately estimate the mass transfer rates and oil recovery from matrix blocks under gravity drainage. The theoretical results using realistic diffusivity coefficients can accurately match the experimentally measured solvent concentration profiles inside the matrix block. Furthermore, an optimization strategy based on the new model is developed that can be used for a quick evaluation of solvent choice for different oil types and reservoir properties.

1. Corresponding authors: Amin Sharifi Haddad, Email:amin.sharifi@abdn.ac.uk, Tel: +44 (0)1224 272977 Fax: +44 (4) 1224272497 
23 Keywords: solvent-based recovery; fractured reservoirs; solvent diffusion; concentration-

24 dependent diffusivity; gravity drainage

\section{Nomenclature}

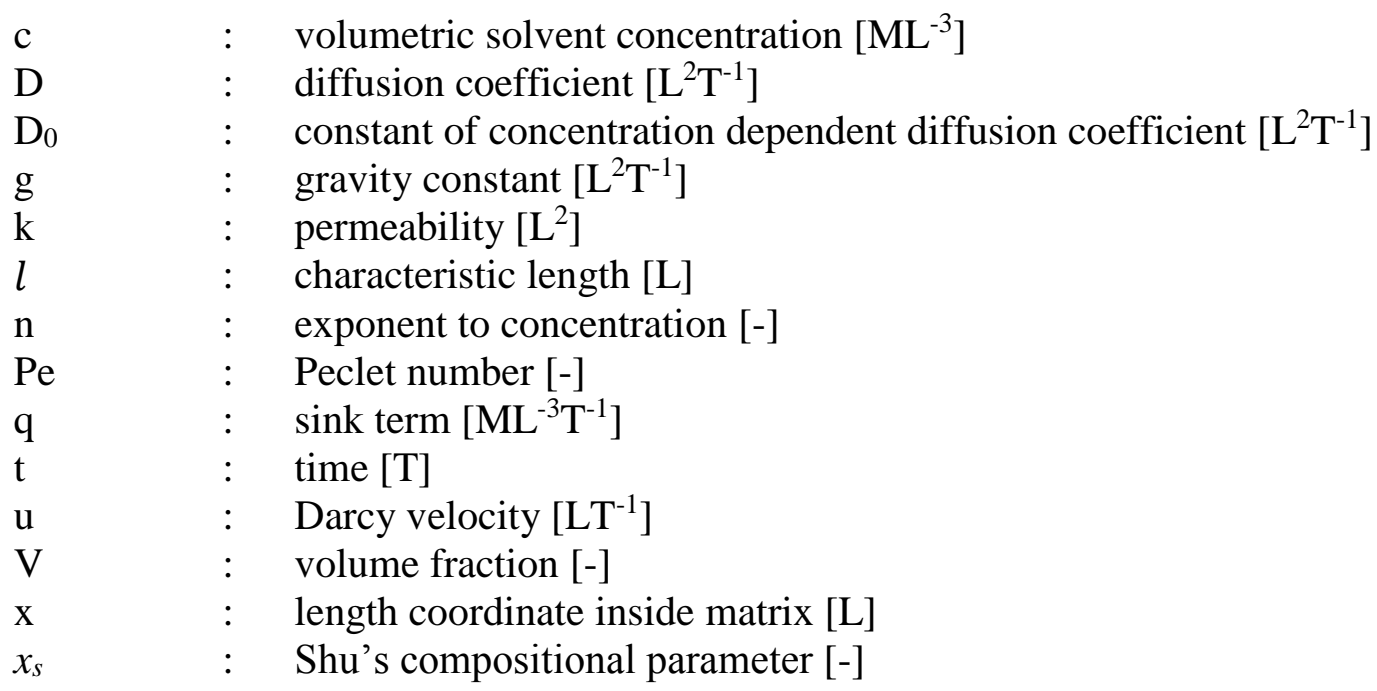

\section{Greek}

$\begin{array}{lll}\alpha & : & \text { empirical constant in viscosity correlation }[-] \\ \phi & & \text { porosity of the matrix }[-] \\ \rho & : & \text { density }\left[\mathrm{ML}^{-3}\right] \\ \mu & : & \text { dynamic viscosity }\left[\mathrm{MLT}^{-1}\right] \\ \nu & : & \text { Kinematic viscosity }\left[\mathrm{L}^{2} \mathrm{~T}^{-1}\right]\end{array}$

\section{Subscript}

$\begin{array}{lll}\mathrm{D} & : & \text { dimensionless } \\ \operatorname{mix} & : & \text { mixture } \\ \mathrm{O} & : & \text { oil } \\ \mathrm{S} & : & \text { solvent }\end{array}$

\section{$27 \quad$ 1. Introduction}

28 High fracture-to-matrix permeability ratio is the main feature of fractured reservoirs that makes

29 oil recovery from these reservoirs difficult in most cases (Saidi 1987). Gravity drainage, 
capillary and viscous forces are important drive mechanisms for oil production from matrix

31 blocks (Karimaie and Torsaeter 2008; Pooladi-Darvish and Firoozabadi 2000). In fractured

32 reservoirs, conventional methods such as water flooding and gas injection have shown good

33 recovery performances (Mattax and Kyte 1962; de Swaan 1978; Karimaie et al. 2007).

34 Also, miscible displacement improves oil recovery from fractured reservoirs (Firoozabadi et al.

35 1997; Torabi et al. 2012). There are huge reserves of heavy oil locked in fractured carbonate

36 reservoirs around the world, for instance in the Middle East, Canada, and Russia (Antoniadi et al.

37 1988; Briggs et al. 1988; Baibakov and Garushev 1989; Ezeuko et al. 2015). In some cases, the

38 oil is not mobile at reservoir conditions. Oil recovery from oil sands and heavy oil reservoirs

39 requires first that the oil viscosity is lowered. This is often accomplished by either thermal

40 processes, i.e. introducing heat to raise the temperature of oil or by solvent dilution, i.e. mixing

41 oil with solvents. Examples are SAGD; steam-assisted gravity-drainage, VAPEX; vapour

42 extraction, ES-SAGD; expanding solvent SAGD, to name a few (Butler and Stevens 1981;

43 Butler and Mokrys 1989, 1991; Dunn et al. 1981; Jiang et al. 2014).

44 Thermal processes that have demonstrated successful commercial performance in oil sands

45 reservoirs have also been proposed to recover heavy oil from fractured rocks (Butler and Mokrys

46 1989, 1989; Pooladi-Darvish and Farouq Ali 1994; Rahnema et al. 2008; Ezeko et al. 2015).

47 However, challenges related to the steam channelling through fractures and vuggy intervals

48 remains unresolved. In these reservoirs, condensate bypasses matrix blocks with matrix heating

49 dominated by conduction; thus it may not yield high recovery factor as encountered in oil sands

50 operations (Penny et al. 2005). 
51 Therefore, using solvents might be a good solution for oil recovery from these reservoirs. The

52 key advantage of miscible hydrocarbon solvents compared to immiscible gas injection is the

53 ability of the solvent to mix completely with the oil (in all proportions). Hence, capillary effects

54 vanish which consequently leads to lower residual oil saturation and higher recovery factor than

55 would be the case with immiscible mixing. In deep reservoirs that are composed of mainly heavy

56 components, use of hydrocarbon gas requires high compression costs to reach miscible

57 conditions. Also in shallow heavy oil reservoirs, use of heavier hydrocarbon solvents are suitable

58 compared to gas injection (Gates 2007; Chahardowli et al. 2013; Pathak et al. 2013; Mayorquin-

59 Ruiz and Babadagli 2016). Oliveira et al. (2009) discussed that oil viscosity and type of the

60 solvent are very important parameters to improve the oil recovery in heavy oil reservoirs. They

61 found that the heavier solvents achieve higher recovery factors which is related to the oil-solvent

62 miscibility development and oil mobilizing by reducing its viscosity.

63 Oil recovery with solvent injection mainly depends on the diffusion of solvent and its mixing due

64 to natural convention in the matrix blocks (Kahrobaei et al. 2012). Diffusion of solvent is a very

65 slow process and is not practical as an enhanced oil recovery method, however, gravity driven

66 convection with counter-current flow is a promising solution for many fractured reservoirs from

67 heavy to light oils (Darvish et al. 2006; Hatiboglu and Babadagli 2008; Rankin et al. 2014;

68 Leyva-Gomez and Babadagli 2016).

69 The impact of diffusion has been studied by several investigators for enhanced oil recovery from

70 fractured reservoirs (Jamshidnezhad et al. 2004; Darvish et al. 2006; Karimaei and Torsaeter,

71 2008). Rich solvents showed important recovery performance in laboratory analysis for fractured

72 rocks (Chahardowli et al., 2013). Hatiboglu and Babadagli (2008) used pentane to understand 
73 flow mechanisms in fractured rocks through micro model studies. They reported that diffusion

74 reduces the viscosity of the oil and then natural density-driven convection triggered by the

75 solvent fingering improves oil-solvent mixing. Trivedi and Babadagli (2008) experimentally

76 analysed the role diffusion process in oil recovery from fractured rocks by using solvents. Their

77 study showed that diffusion and injection rate affect final recovery. At an optimum injection rate

78 where solvent can diffuse from fracture into the matrix block, viscosity reduction due to solvent

79 mixing, increases the recovery factor. Kahrobaie et al. (2012) analysed X-ray tomography of

80 solvent concentration and oil recovery from core samples. Their study suggested that diffusion of

81 solvent into the rock matrix block and then subsequent mixing helped to mobilize oil from

82 matrix blocks. They attempted to simulate their experiment with a reservoir simulator (Shell's

83 MoReS simulator). However, in some cases, the software was not capable of reproducing the

84 experimental data with reasonable values of the diffusion coefficient. To get a match between the

85 simulation results and experimental data, they used diffusion coefficients with orders of

86 magnitude smaller than those reported in the literature. Against these promising experimental

87 results for solvent enhanced oil recovery, models and simulators are not able to fully incorporate

88 full diffusion behaviour observed in experiments (Kahrobaie et al. 2012). This includes diffusion

89 coefficient dependence on temperature and concentration. This dependence has been found

90 necessary for other solvent-based processes (Trivedi and Babadagli 2008).

91 In this study a model is developed to describe mass transfer process in miscible enhanced oil

92 recovery method from fractured reservoirs. A concentration dependent diffusion coefficient is

93 used for the solvent-oil system. Simulation results are compared for different solvent and oil

94 properties, and, optimization of solvent is discussed. 


\section{Conceptual Model}

96 We define the fracture geometry as parallel planar gaps which separate slab-shaped matrix

97 blocks. Figure 1 shows the schematic of fracture and matrix block. It is assumed that a repetitive 98 element shown in this model represents a matrix block surrounded by fracture in the reservoir. In

99 this model, one dimensional diffusion and flow inside the matrix block perpendicular to the 100 fracture plane occur. We assume that the oil mobility is very low, initially, due to its very high

101 viscosity. The main oil recovery mechanism from the matrix block is oil dilution through 102 solvent-oil diffusion and consequently gravity drainage, i.e. denser diluted oil is replaced by 103 lower density solvent. Thus a density contrast between oil and injected solvent is required to 104 augment the gravity drainage process. Typically, solvents have lower density than oil. It is 105 assumed that solvent fills the fractures where permeability is high, and its concentration inside 106 the fractures is reasonably constant. Also oil expansion (swelling) is assumed to be negligible. 107 The mass transfer process initially starts with solvent diffusion into the matrix block from the 108 interface of matrix-fracture where solvent concentration is constant. As solvent diffuses into the 109 matrix block, it mixes with oil and reduces oil viscosity. Thereafter, a counter-current flow is 110 triggered due to the density contrast between the solvent and oil-solvent mixture. This counter111 current flow develops dispersion in the matrix block (convective mixing). The process continues 112 until solvent penetrates the entire matrix.

\section{$113 \quad 3 . \quad$ Mathematical Model}

114 One dimensional flow of solvent and oil happens at the interface of matrix and fracture. The rate 115 of solvent penetration into the matrix block and oil flow to the fracture are key. Thus, we 
116 develop a model which describe the mass transfer process in a matrix block and gives the

117 corresponding oil flow rate based on the fluids and rock properties of the system. Mass transfer

118 process at the matrix block is controlled initially by Fick's second law at the interface of solvent

119 and oil, and then Darcy's law controls the gravity drainage. Therefore, the counter-current flow

120 of oil and solvent can be expressed by coupling of continuity equation and Darcy's law as a

121 nonlinear diffusion equation which counts for convective and diffusive mass transfer (Marle,

122 1981):

$123 \quad \frac{\partial c}{\partial t}=\frac{\partial}{\partial x}\left(D \frac{\partial c}{\partial x}\right)-\frac{1}{2 \phi} \frac{\partial}{\partial x}(u c)+\Delta q$

124 where $c$ is the volumetric solvent concentration, $t$ is time, $D$ is effective solvent diffusion

125 coefficient, and $x$ is coordinate perpendicular to the interface plane of fracture and matrix and $\phi$

126 is the matrix porosity. $\Delta q$ is the sink term which represents the counter-current flow of the

127 mixture of solvent and oil toward the fracture plane (for solvents heavier than oil), or toward the

128 middle of matrix block (for solvents lighter than oil), and has a unit of mass per volume

129 per time. Theoretically it has the same magnitude as convective term but flow happens in

130 opposite direction of convective term. It is assumed that produced mixture at the interface of

131 matrix-fracture is recovered immediately, i.e., fracture is always saturated with solvent.

132 Therefore, in Equation (1) convective and counter-current terms contribute to the solvent flow

133 due to gravity force. Due to full miscibility condition, half of the cross sectional area is available

134 to convective flow and the other half is available to counter-current flow, therefore, there is a

135 coefficient of 0.5 in front of convective term. We further assume ideal mixing, i.e. volume

136 remains perfectly additive upon mixing. In the above equation, the velocity is given by: 
$137 u=-\frac{k k_{r} g}{\mu} \Delta \rho$

138 where $k$ and $k_{r}$ are matrix absolute and relative permeabilities (relative permeability is equal to

139 unity for miscible conditions), g represents constant of gravity, $\Delta \rho$ is the difference between

140 mixture density at any two points that causes a change in hydraulic head and therefore gravity

141 drainage of oil. This density difference is a function of solvent concentration. And $\mu$ is viscosity

142 of the mixture of oil and solvent.

143

144 Initial and boundary conditions for Equation (1) are:

145

$146 \quad c(x, t)=0, \quad t=0,0 \leq x \leq l$

$147 \quad c(x, t)=c_{s}, \quad t>0, x=0$

$148 \quad \frac{\partial c(x, t)}{\partial x}=0, \quad t>0, x=l$

149

150 where $l$ is the characteristic length of the rock matrix blocks; which is the half length of the

151 matrix block if fracture planes are extending vertically (gravity assisted flow happens from both

152 sides of fracture planes), or it is equal to the fracture spacing for horizontal fracture planes

153 (gravity assisted flow happens from lower fracture plane) as shown in Figure 1.

154 There are different correlations in the literature for the concentration-dependent viscosity profiles

155 such as log-linear and power-function mixing rules (Lederer 1933; Shu 1984). We use a power-

156 function to define the oil-solvent mixture viscosity as:

$157 \quad \frac{1}{\mu_{\mathrm{mix}}}=\frac{1}{\mu_{\mathrm{o}}}\left(\frac{\mu_{\mathrm{o}}}{\mu_{\mathrm{s}}}\right)^{x_{s}}$ 

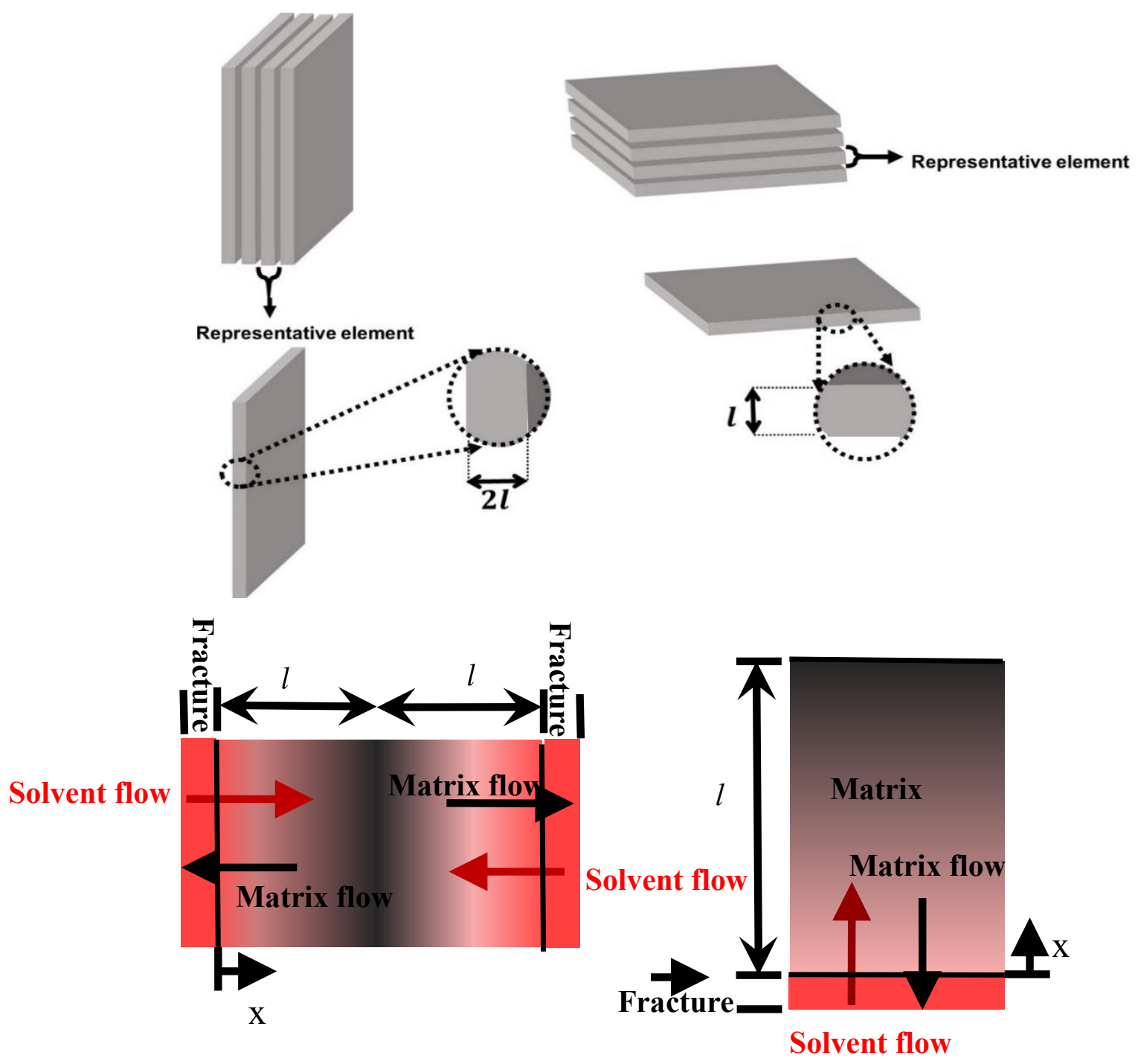

Figure 1: Schematic of planar matrix blocks and characteristic length based on the fracture

161 orientation.

163 where $\mu$ is the viscosity of the mixture (subscribe 'mix') or oil and solvent phase (subscribe 'o' 164 or 's' respectively). $x_{s}$ is a compositional parameter defined by Shu (1984): 
$165 \quad x_{\mathrm{s}}=\frac{V_{\mathrm{s}}}{\alpha V_{\mathrm{o}}+V_{\mathrm{s}}}$

166 where $V_{o}$ and $V_{s}$ are volume fractions of oil and solvent in the mixture, same as concentration,

167 and $\alpha$ is an empirical constant have a value between zero and one. We used 0.6 in this study

168 based on the typical values reported in Shu's work (1984). For the density of the mixture, a

169 simple volumetric mixing rule is used as:

$170 \rho=\rho_{\mathrm{s}} V_{\mathrm{s}}+\rho_{\mathrm{o}} V_{\mathrm{o}}$

171

172 Based on the previous laboratory and modelling studies (Guerrero et al. 2008; Okazawa 2009;

173 Diedro et al. 2015) it is reported that diffusion coefficient is not constant, rather it is a

174 concentration dependent parameter. In this study we use the model suggested by Okazawa (2009)

175 for concentration dependency of the diffusion coefficient:

$176 \quad D(c)=D_{0}\left(\frac{c}{c_{\mathrm{s}}}\right)^{\mathrm{n}}$

177

178 In Equation (7), $D$ is concentration dependent diffusion coefficient, $D_{0}$ is constant of

179 concentration dependent diffusion coefficient, and $\mathrm{n}$ is the exponent to concentration for

180 diffusion coefficient; typically between 1-4 for oil and solvent system. This equation has been

181 developed based on experimental tests with different heavy oils and solvents. Once these

182 functions of diffusion coefficient, density and viscosity of mixture are applied to the formulation

183 of mass transfer in matrix block, it gives a partial differential equations with two nonlinear terms.

$184 \quad \frac{\partial c}{\partial t}=\frac{\partial}{\partial x}\left(D_{0}\left(\frac{c}{c_{s}}\right)^{n} \frac{\partial c}{\partial x}\right)+\frac{1}{2 \phi} \frac{\partial}{\partial x}\left(\left(\frac{\mu_{\mathrm{o}}}{\mu_{\mathrm{s}}}\right)^{x_{s}} \frac{k g}{\mu_{\mathrm{o}}} \Delta \rho c\right)+\Delta q$

185 Using dimensionless variables, Equation (8) can be written as: 
$186 \frac{\partial c_{\mathrm{D}}}{\partial t_{\mathrm{D}}}=\frac{\partial}{\partial x_{\mathrm{D}}}\left(c_{\mathrm{D}}^{\mathrm{n}} \frac{\partial c_{\mathrm{D}}}{\partial x_{\mathrm{D}}}\right)+\frac{P e}{2} \frac{\partial}{\partial x_{\mathrm{D}}}\left(\mu_{\mathrm{D}}^{\mathrm{x}_{\mathrm{S}}} \rho_{\mathrm{D}} c_{\mathrm{D}}\right)+q_{\mathrm{D}}$

188 where

$189 \quad \mu_{\mathrm{D}}=\frac{\mu_{\mathrm{o}}}{\mu_{\mathrm{s}}}$

$190 \quad c_{\mathrm{D}}=\frac{c}{c_{\mathrm{s}}}$

$191 \quad x_{\mathrm{D}}=\frac{x}{l}$

$192 t_{\mathrm{D}}=\frac{t D_{0}}{l^{2}}$

$193 \rho_{\mathrm{D}}=\frac{\Delta \rho}{\rho_{\mathrm{o}}}$

$194 P e=\frac{k g l}{D_{0} v_{\mathrm{o} \phi}}$

$195 \quad q_{\mathrm{D}}=\frac{\Delta q l^{2}}{D_{0} c_{S}}$

197 In the above equation, $P e$ is the Peclet number which is the ratio of the convective to diffusive

198 terms. A Peclet number of zero corresponds to pure diffusion mass transfer process, and values

199 greater than zero signify convective mixing and gravity drainage in the oil recovery process in 200 addition to the diffusion process.

201 Due to the nonlinearity of Equation 8, we cannot provide a closed form analytical solution. Thus 202 we solve Equation 8 numerically to find the evolution of solvent concentration distribution in the 203 matrix block and consequently evaluate oil production. And oil recovery factor can be estimated 204 through a numerical integration of the solvent concentration over the matrix block height at any 205 time. We use central finite difference for mass diffusion and convection terms and forward 
difference for marching in time. It should be noted that for the diffusion coefficient, downwind formulation is used as similar to the direction of solvent penetration, however, for density and viscosity of the mixture upwind formulation is considered as convective and counter-current flow starts in the opposite direction of solvent penetration.

\section{Numerical solution and comparison with experimental data}

To validate our model, we compare the simulation results of our model with experimental data.

We simulate the solvent penetration depth and oil recovery for an experimental study reported as a nearly one-dimensional (1D) flow for oil recovery from a matrix block (Kahrobaei et al., 2012). They used hexadecane as oil and decalin as solvent in low permeability core sample.

Table 1 shows the details of the rock and fluid properties used in the experiment. They showed that the solvent concentration increases inside the rock matrix with time as oil is produced due to gravity drainage. They used CT-scan at various times and found the concentration profiles inside the core sample by CT-scan image analysis. They reported up to $100 \%$ oil recovery which indicates a miscible single phase process. In the same study, Kahrobaei et al. (2012) performed numerical simulations of the process by using a multiphase reservoir simulator (Shell's MoReS). Their simulations results demonstrate that reproducing solvent concentration profile inside the rock matrix blocks may not be achievable. Moreover, the oil recovery profile was not matched with a reasonable value of the diffusion coefficient values.

By using experimental values for oil, solvent and rock properties, we simulate the process with $P e$ number and viscosity ratio of 0.25 and 1.05 , respectively, extracted from reported experimental data. Figure 2a-b depicts concentration and oil recovery profiles (solid lines) from 
228 our numerical simulation, respectively. For comparison purposes, in Fig.2a-b, we also plot the

229 reported experimental solvent concentration data and recovery (dotted lines) from Kahrobaei et

230 al. (2012). Figure 2 demonstrates that the new model proposed here predicts the solvent

231 concentration profile in the core and total recovery factor from the rock matrix block reasonably

232 well. All parameters are from the experimental study. The matching parameters in our model are

$233 n$ and $D_{0}$ which are chosen to be 2 and $1.75 \times 10^{-8} \mathrm{~m}^{2} / \mathrm{s}$ respectively. The value of $D_{0}$ is in the

234 range of reported values for solvent diffusion coefficient into oil (Guerrero et al., 2008;

235 Okazawa, 2009; Diedro et al., 2015). Concentration dependent diffusion coefficient was

236 developed based on the experimental data from heavy oil and solvent mixtures, and with the lack

237 of enough experimental data for light oil-solvent mixtures, we assume this concentration

238 dependent diffusion coefficient is applicable for other oil viscosities as well. Also the study of

239 Kahrobaei et al. (2012) showed that diffusion coefficient in their numerical simulation should be

240 very small to capture the behaviour of solvent diffusion, therefore, the concentration dependent

241 diffusion coefficient might be the reason for such behaviour. Further studies are required to

242 confirm this correlation of concentration dependent diffusion coefficient for light oil-solvent

243 mixtures.

244 Table 1 Fluid and rock properties used in the experimental study (Kahrobaei et al. 2012)

\begin{tabular}{ll} 
Property & Value \\
\hline Oil (hexadecane) viscosity & $3.507 \mathrm{cP}$ \\
Solvent (decalin) viscosity & $3.355 \mathrm{cP}$ \\
Core porosity & $21 \%$ \\
Core permeability & $20 \mathrm{mD}$
\end{tabular}


Temperature

$20^{\circ} \mathrm{C}$

246 It should be noted that the original experiment is performed in a cylindrical core samples when

247 the whole sample is submerged into the solvent container. This allows for additional oil recovery

248 resulting from the side of cylinder in addition to the bottom side. However, CT images of the

249 experiment that we modelled in this study depict that the solvent penetration and oil production

250 is very small which justifies the 1D assumption. On the other hand, this small additional oil

251 production could be the source of discrepancy between the model and experimental data in

252 Figure 2a. However, it is a small deviation as seen between the recovery factors calculated from

253 the model and reported experimental values as shown in Figure 2b.
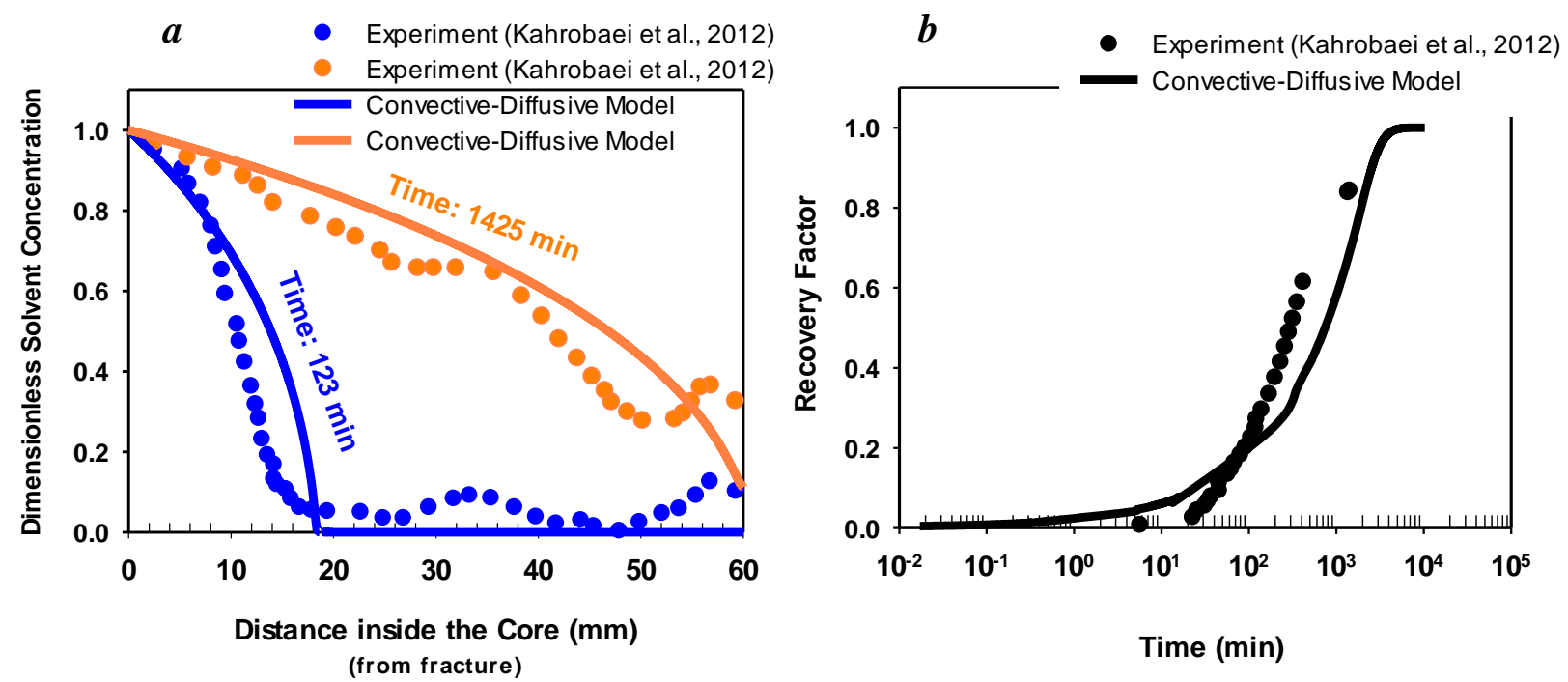

255 Figure 2. a) Solvent concentration profile at two different times inside the core, b) recovery

256 factor of the solvent enhanced gravity drainage

$257 \quad$ 5. Parametric studies 
258 In the previous section, we demonstrate the capability of the proposed model to represent solvent

259 penetration depth and oil recovery for the core scale experiments. In this section, we examine the

260 effect of different parameters for a solvent-enhanced gravity drainage recovery from a matrix

261 block in fractured rocks including Peclet number, viscosity, and density contrasts and the

262 concentration dependency of diffusion coefficient by varying the $\mathrm{n}$ exponent. In fact, all of these

263 parameters are controlled by solvent choice. Hence, it is important to choose the right solvent

264 based on the petrophysical properties that are used in Peclet number, dimensionless density and

265 viscosity definitions, and $\mathrm{n}$ exponent for any field before making decision of enhanced oil

266 recovery methods.

267

268 Peclet number: Figure 3 shows the solvent concentration profiles at different times for Peclet

269 number and viscosity ratios of 1 and 100, respectively. It can be seen that the concentration

270 increases from the interface of fracture and matrix as it diffuses into the matrix block, mixes with

271 oil, and reduces the oil viscosity. Diluted oil drains towards the fracture due to the gravity. In the

272 other words, the process starts with diffusion dominant mass transfer and then it transitions to

273 convective mixing and gravity drainage. It should be noted that at the front of solvent and oil

274 interface, there is a sharp change in solvent concentration profile. This behaviour is due to

275 exponential concentration dependency of the diffusion coefficient, similar trends were reported

276 for VAPEX process with concentration dependent diffusion coefficient (Okazawa, 2009). Since

277 solvent concentration ahead of interface is zero, it is assumed that there is no convective term,

278 and just behind the interface where solvent concentration is non-zero, convection contributes to 
279 the flow of oil toward fractures, therefore, there would be a rapid change in solvent

280 concentration.

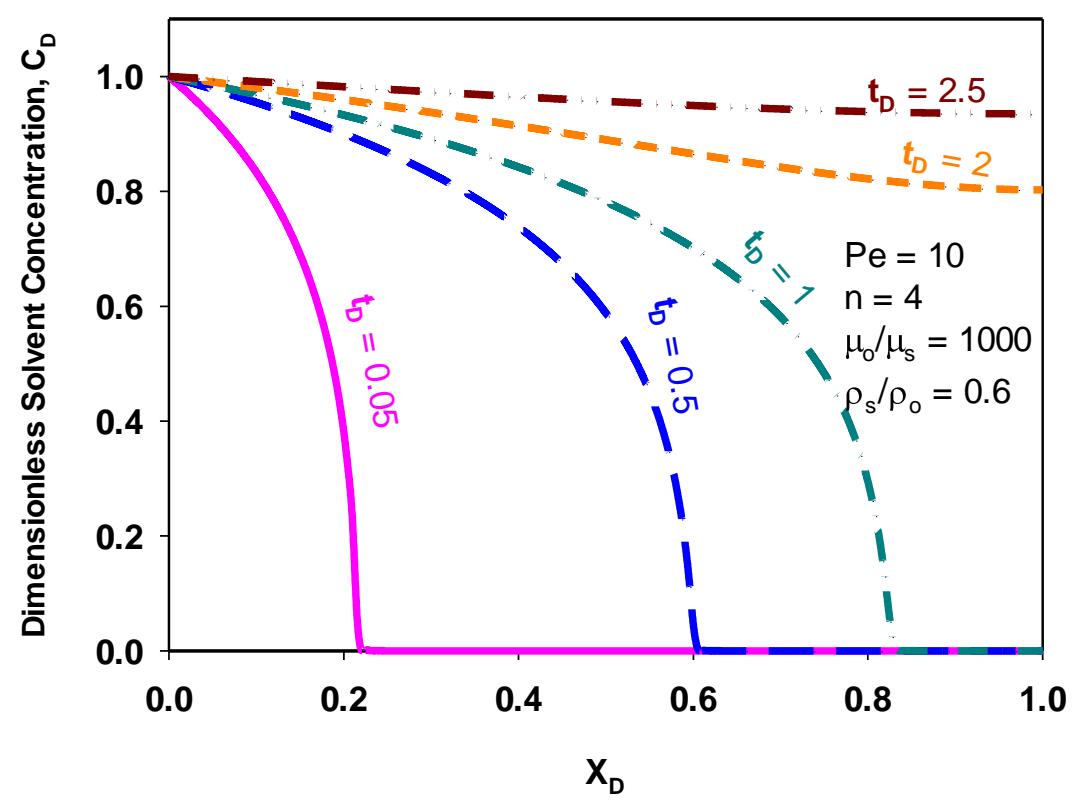

Dimensionless Distance inside the Matrix (from Fracture)

282 Figure 3: Concentration profile along the matrix block at different dimensionless time.

284 Figure 4 demonstrates the effect of Peclet number on the recovery of oil from matrix block.

285 Figure 4a shows that as Peclet number increases, the depth of solvent penetration increases.

286 Recovery factors are also shown in Figure $4 \mathrm{~b}$ for different Peclet numbers. For Peclet numbers

287 less than ten, diffusion is dominant compared to convection. Hence, the impact of convection on

288 oil recovery factor becomes insignificant. In Figure 4c, we compare solvent concentration profile

289 inside the matrix block for two Peclet numbers at early and late times. The results show that the

290 difference between the penetration depths increases as the solvent assisted recovery process

291 continues, which reveals that convective flow becomes dominant at extended time. 

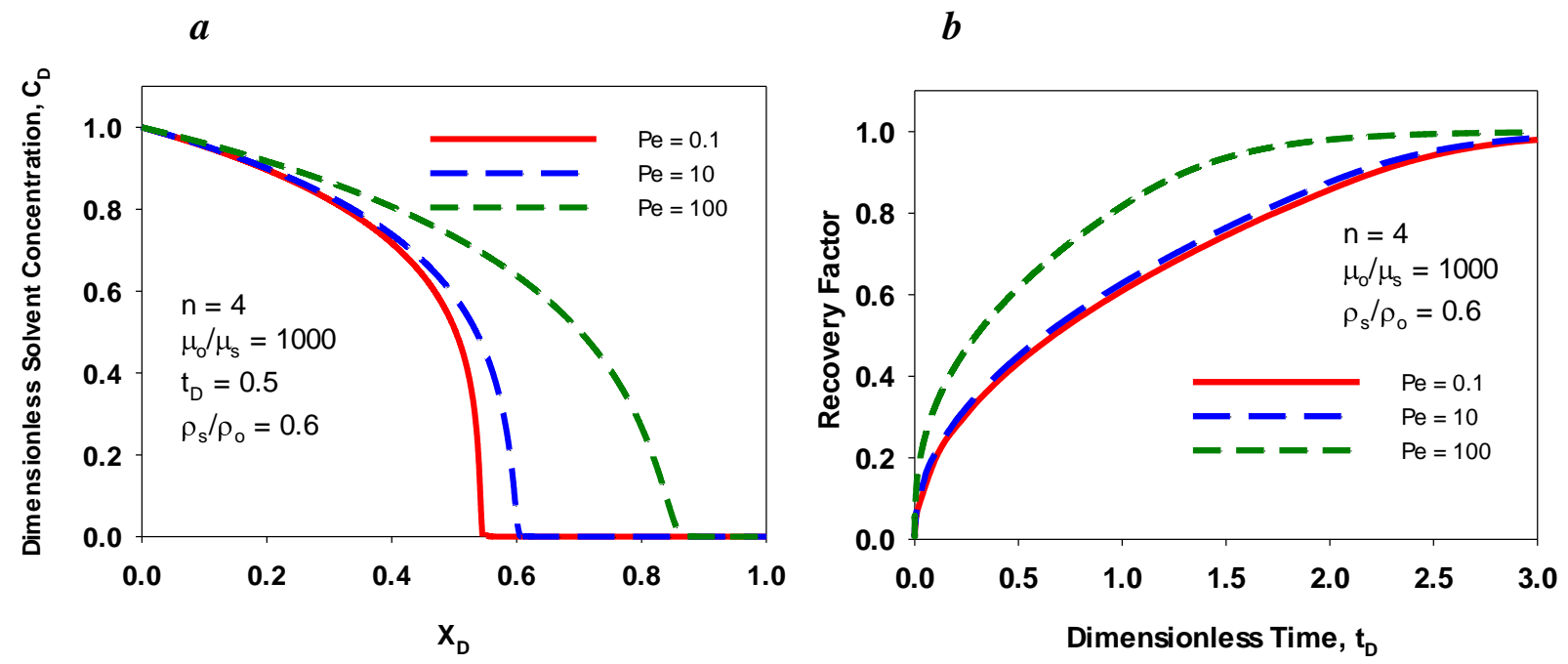

Dimensionless Distance inside the Matrix (from Fracture)

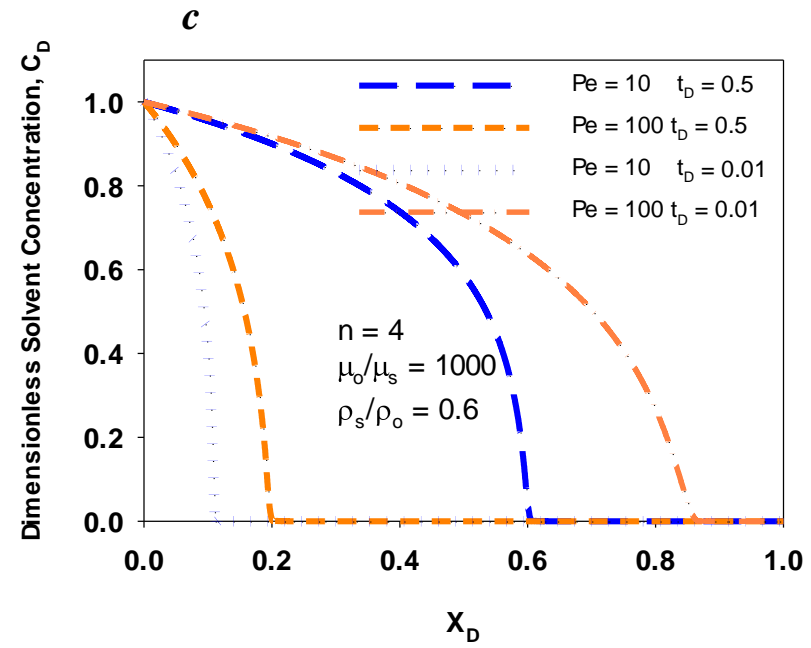

Dimensionless Distance inside the Matrix (from Fracture)

293 Figure 4: Comparison of the Peclet numbers, a) solvent concentration profile in the matrix block 294 at dimensionless time of 0.5, b) oil recovery factor, c) solvent concentration in the matrix block 295 for two Peclet numbers at two dimensionless times.

296 Solvent viscosity: Solvent viscosity is another parameter which controls fluid mixing or relative

297 movement of each component in porous media. Figure 5 compares the concentration profiles and 298 oil recoveries resulted from three different oil-solvent viscosity ratios. Lower solvent viscosity 
translates to a higher mobility of oil-solvent mixture and in turns, to more rapid oil drainage from rock matrix block. Therefore, higher oil to solvent viscosity ratio which is due to different types of solvent (with one type of oil) in the recovery process shows better recovery performance as oil viscosity can be decreased to a lower order while all other parameters are kept constant.
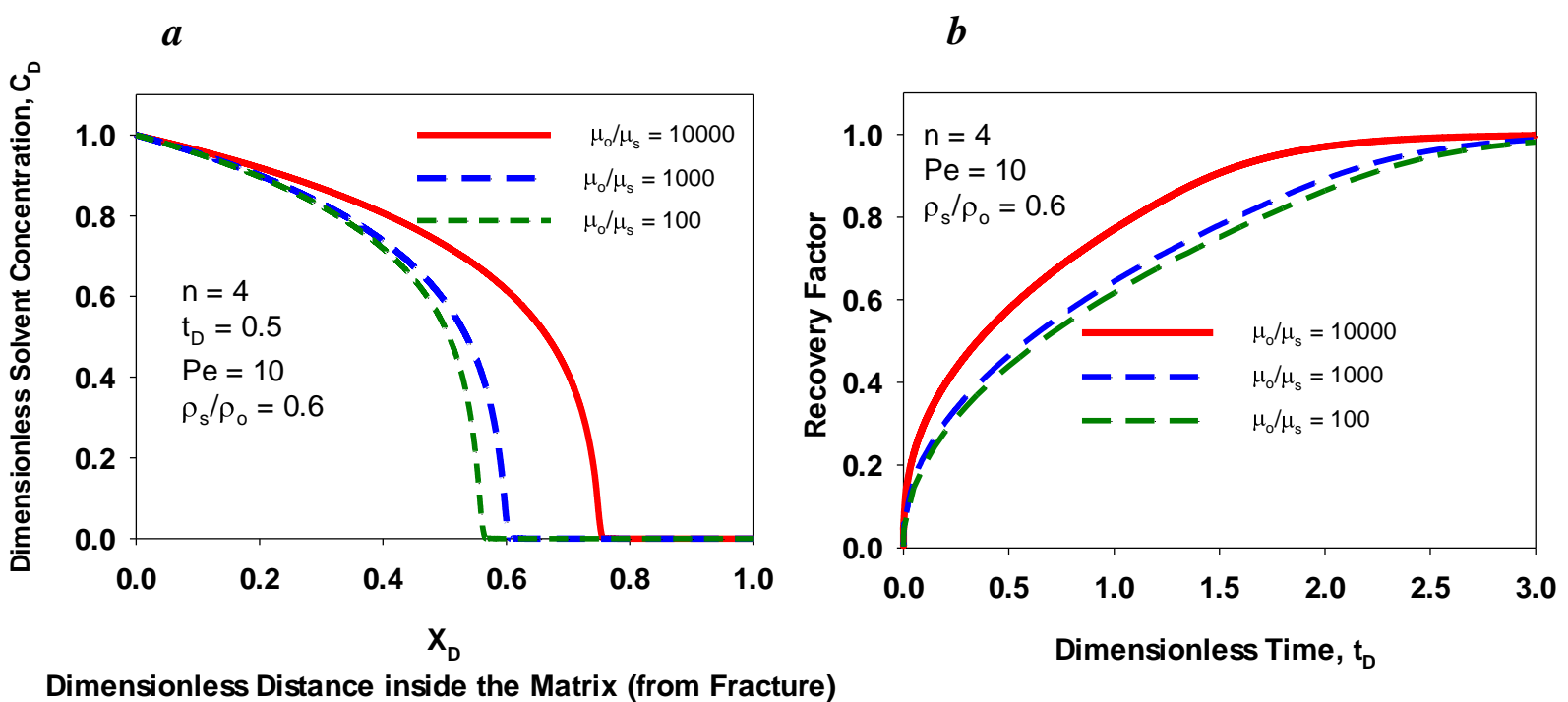

Figure 5: Comparison of the viscosity ratios (two oil with one order of magnitude difference in their viscosity), a) solvent concentration profile in the matrix block at dimensionless time of 0.5 , b) oil recovery factor.

Concentration dependent diffusion (n-Constant): Petrophysical properties and viscosity of fluids, which are discussed through the effects of Peclet number and viscosity ratio are directly

309 related to the convective mixing and gravity drainage process. Diffusive mass transfer is another key parameter which determines the rate of mass diffusion of solvent into the oil phase. So, its

311 dependency on concentration is a key factor in controlling the depth of solvent penetration.

312 Therefore, we study the effect of exponent to concentration, i.e. $n$-Constant. Figure 6 shows that 
313 typical values of exponent can influence the rate of mass diffusion and recovery process from

314 rock matrix block. Solvents which mix easily with oil have a lower exponent values and

315 therefore result in higher recovery factors at a shorter time period.
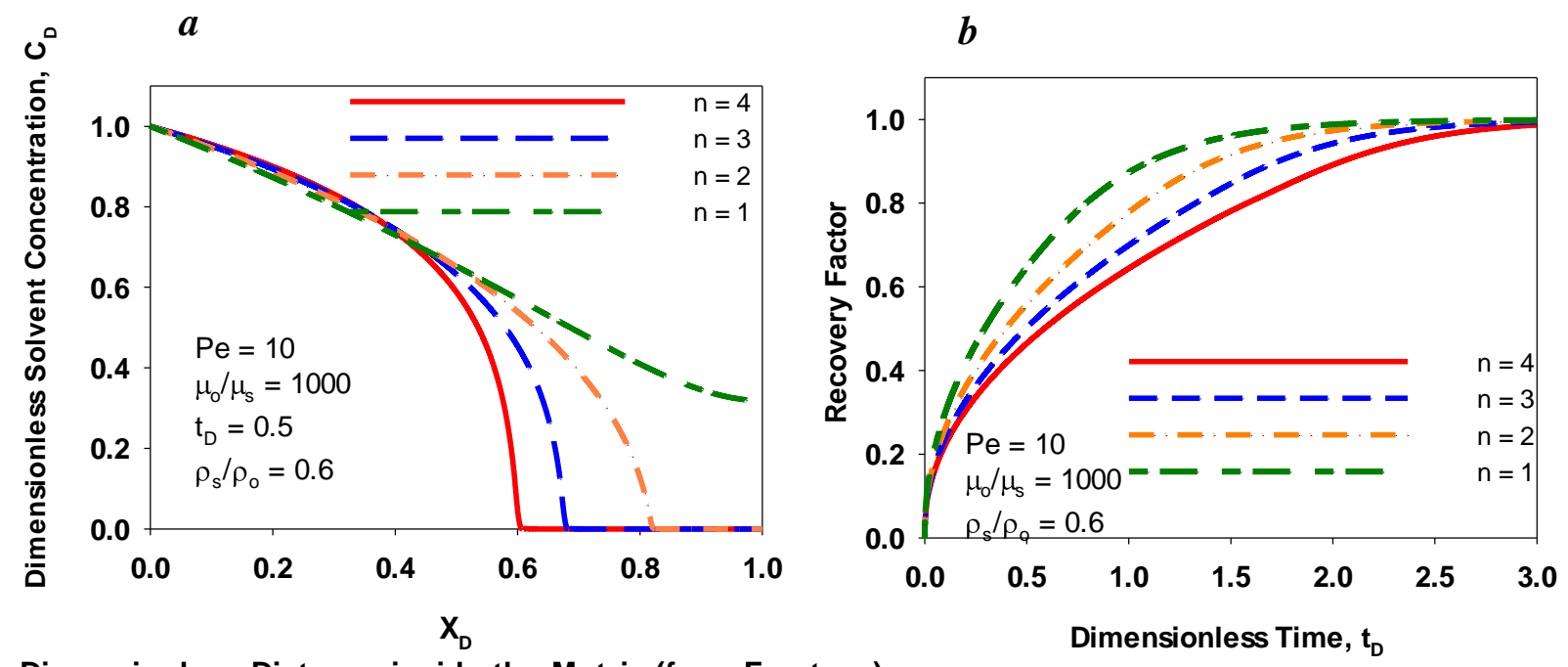

Dimensionless Distance inside the Matrix (from Fracture)

317 Figure 6: Effect of different exponent to concentration for diffusion coefficient, a) solvent concentration profile in the matrix block at dimensionless time of $0.5, b$ ) oil recovery factor.

\section{Solvent density to oil density ratio}

Another parameter that can affect the rate of oil recovery in a gravity drainage process is density difference between solvent and oil. In this study this difference is developed in the dimensionless

322 form of density ratio of solvent to oil. Most solvents are less dense than oil, therefore, this ratio is 323 typically less than unity. However, for small Peclet numbers, i.e., <10, the effect of density ratio 324 is negligible since convection is not dominant. Figure 7 shows the effect of density ratio for two 325 different solvents with density ratios of 0.6 , and 0.8 at the Peclet number of ten. It can be seen 326 that as the ratio increases, oil recovery become slower which means gravity force becomes less 
327 effective. Use of light solvents which raises the density contrast is favourable, however, it should

328 be noted that light solvents have smaller diffusion coefficients that makes the mass transfer

329 process slow. Thus, an optimum solvent to provide enough gravity force with an effective

330 diffusive mass transfer process needs to be determined.
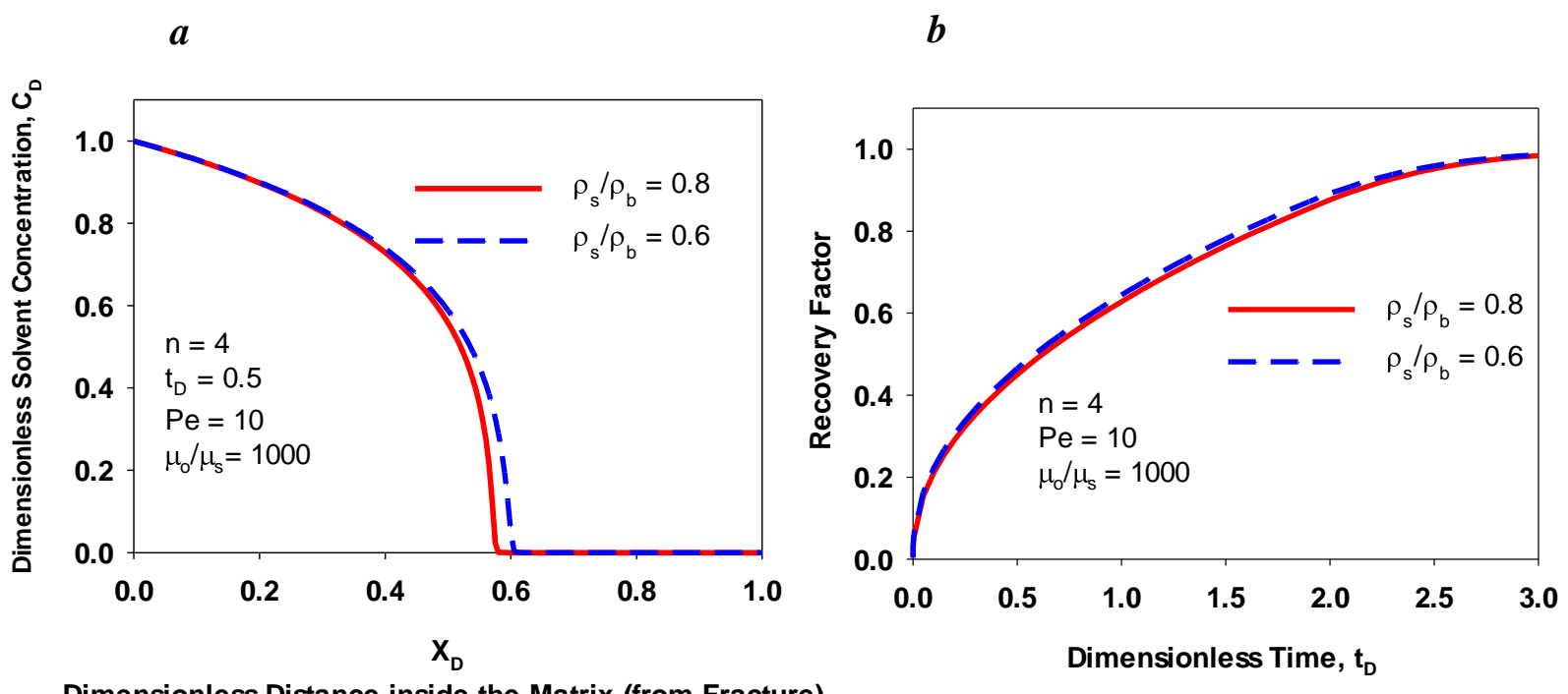

331

Dimensionless Distance inside the Matrix (from Fracture)

332 Figure 7: Effect of oil to solvent density ratio, a) solvent concentration profile in the matrix

333 block at dimensionless time of $0.5, \mathrm{~b}$ ) oil recovery factor.

\section{Solvent optimization}

To design a successful solvent assisted gravity drainage recovery process for fractured reservoirs, all parameters discussed in previous section should be thoroughly investigated. This

337 means that based on the properties of oil, rock, and solvent, a desired recovery process can be optimized. We used these parameters to determine solvent type required to recover oil from a matrix block. Different exponents for concentration dependence of diffusion coefficient are considered separately for different optimizations. The algorithm shown in Figure 8 depicts how 
341 optimized solutions are determined. Once it is run for each exponent values, it provides an 342 optimum value for the desired recovery factor. We show the results for the recovery factor of $34390 \%$, as a target, for other recovery factors same procedure can be performed. An example of 344 optimization graphs is shown in Figure 9. These graphs are associated with exponents of 1 to 4. 345 It can be seen that as the exponent decreases from 4 to 1 , the time required to produce oil 346 decreases. Also each of the plots show that higher Peclet numbers deplete the matrix block faster 347 especially in higher oil-to-solvent viscosity ratios.

348 Based on the laboratory analysis, once the exponent is determined for the solvent and oil, then 349 appropriate graph shows the time required to recover oil from a matrix block (Peclet number and 350 viscosity ratio can also be evaluated from laboratory data). This helps to estimate the operational 351 cost, time, and the solvent required to run a solvent assisted gravity drainage oil recovery from a 352 fractured reservoir. 
Oil properties (viscosity, density)

Range of solvents properties

(viscosity, density, diffusion

Coeff.)

Range of oil to solvent

viscosity ratio

Range of Peclet number

Specify the target RF\%

Run the program for different

' $n$ ' values

354 Figure 8: Optimization algorithm for specific oil properties. 

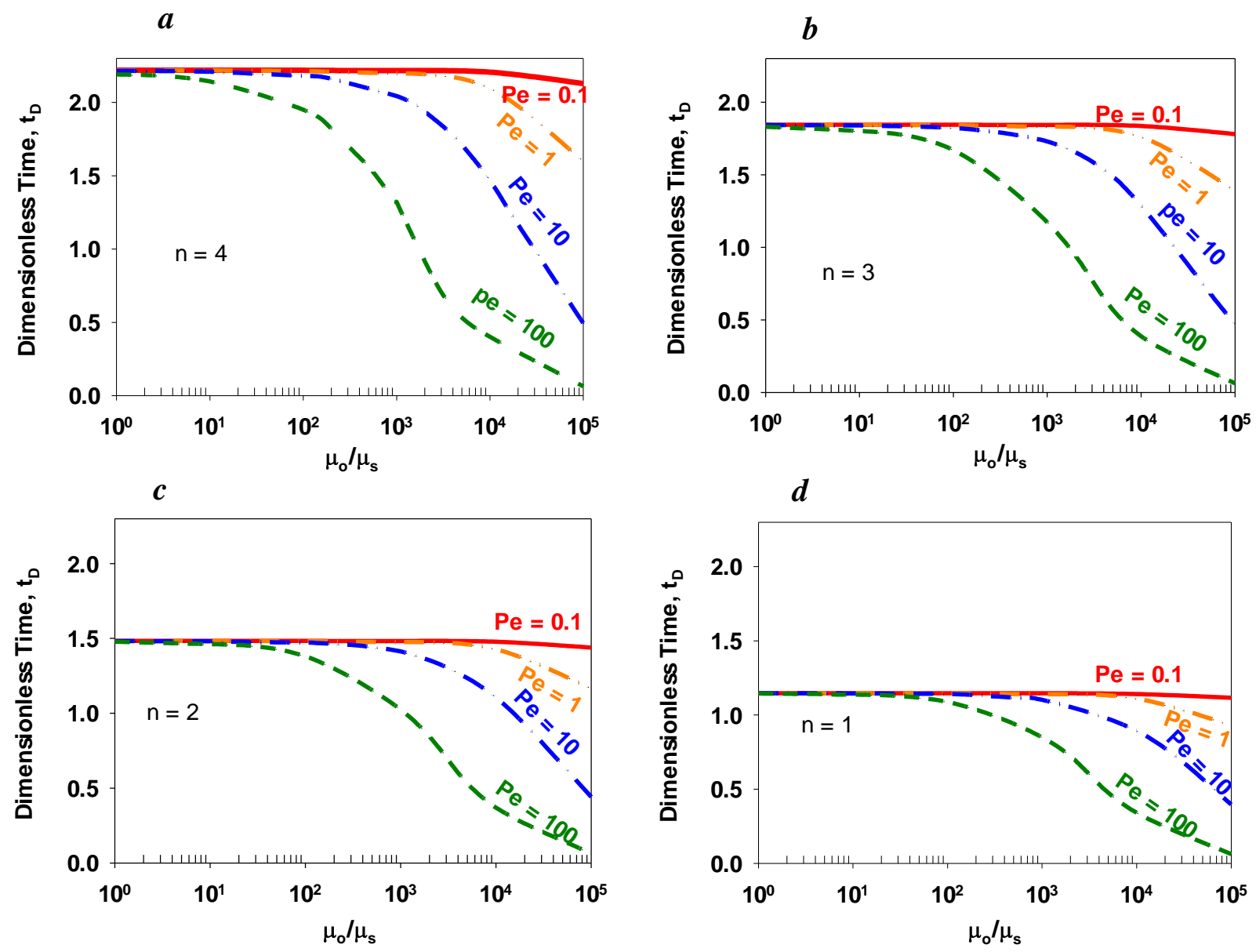

Figure 9: Optimized graphs for recovery factor of $90 \%$ with oil to solvent density of 0.6.

\section{Conclusions}

359 A model for fluid exchange between rock matrix block and its surrounding fracture is developed

360 for solvent-aided gravity drainage. Low to high viscosity oil in fractured reservoirs where the

361 permeability of matrix block might range from low to high values, can be analysed with the use

362 of this model for solvent enhanced gravity drainage processes. Mass transfer, concentration

363 dependent diffusion coefficient, and convective mixing were used to demonstrate the solvent 
364 enhanced gravity drainage process in a single matrix block. The new model can accurately

365 simulate solvent concentration profiles and oil recoveries from matrix blocks reported in solvent

366 recovery experiments. Optimization of the recovery factor yields estimates of the time required

367 to produce oil with a specific solvent. The method provides an easy and fast algorithm to choose

368 the best solvents for gravity drainage recovery processes. This model can be implemented into

369 the multi-phase flow simulators for accurate designs of solvent enhanced oil recovery processes

370 from fractured reservoirs.

\section{$371 \quad$ References}

372 Antoniadi, D.G., Budnikov, V.F., Garushev, A.R.: High viscosity oil recovery from carbonate

373 reservoirs by thermal methods. In: UNITAR/UNDP Conference on Heavy Crude and Tar

374 Sands, Calgary, Canada (1988)

375 Baibakov, N.K., Garushev, A.R.: Thermal methods of petroleum production. Elsevier

376 Publishing Company, New York, N.Y. (1989)

377 Briggs, P.J., Baron, R.P., Fulleylove, R.J., Wright, M.S.: Development of heavy oil reservoirs.

378 J. Pet. Technol. 40(2): 206-214 (1988) doi: http://dx.doi.org/10.2118/15748-PA

379 Butler, R.M., Mokrys, I.J.: Solvent analog model of steam-assisted gravity drainage. AOSTRA

380 J. Res. 59 (1), 17-32 (1989)

381 Butler, R.M., Mokrys, I.J.: A new process (VAPEX) for recovering heavy oils using hot water

382 and hydrocarbon vapour. J. Can. Pet. Technol. 30 (1), 97-106 (1991) 
383 Butler, R.M., Stevens, D.J.: The gravity drainage of steam-heated heavy oil to parallel

384 horizontal wells. J. Can. Pet. Technol. 20 (2), 90-96 (1981)

385 Chahardowli, M., Zholdybayeva, A., Farajzadeh, R.: Solvent-enhanced spontaneous imbibition 386 in fractured reservoirs. In: EAGE Annual Conference \& Exhibition incorporating SPE Europec, 387 London, UK, 10-13 June 2013. European Association of Geoscientists \& Engineers.

388 Darvish, G.R., Lindeberg, E.G.B., Holt, T., Kleppe, J., Utne, S.A.: Reservoir- condition 389 laboratory experiments of $\mathrm{CO}_{2}$ injection into fractured cores. In: SPE Europe/EAGE Annual 390 Technical Conference and Exhibition, Vienna, Austria, 12-15 June 2006. Society of Petroleum 391 Engineers. doi: http://dx.doi.org/10.2118/99650-MS

392 de Swaan, A.: Theory of waterflooding in fractured reservoirs. SPE J. 18(2), 117-122 (1978)

393 Diedro, F., Bryan, J., Kryuchkov, S., Kantzas, A.: Evaluation of diffusion of light hydrocarbon 394 solvents in bitumen. In: SPE Canada Heavy Oil Technical Conference, Calgary Canada, 9-11 395 June 2015. Society of Petroleum Engineers.

396 Dunn, S.G., Nenniger, E.H., Rajan, V.S.V.: A study of bitumen recovery by gravity drainage of 397 heavy oil using low temperature soluble gas injection. Can. J. Chem. Eng. 67 (6), 978-991 $398 \quad$ (1989)

399 Ezeuko, C.C., Wang, J., Kallos, M.S., Gates, I.D.: Towards the development of bitumen 400 carbonates: an integrated analysis of Grosmont steam pilots. Oil Gas Sci. Technol. 70 (6), 983$401 \quad 1005(2015)$ 
402 Firoozabadi. A., Markeset, T., Dindoruk, B.: Viscous displacement in fractured porous media.

$403 \quad$ J. Can. Pet. Technol. 36(9), 50-62 (1997)

404 Gates, I.D.: Oil phase viscosity behaviour in expanding solvent steam-assisted gravity drainage.

405 J. Pet. Sci. Eng. 59, 123-134 (2007)

406 Guerrero-Aconcha, U.E., Salama, D., Kantzas, A.: Diffusion coefficient of n Alkanes in heavy

407 oil. In: SPE Annual Technical Conference and Exhibition, Denver, Colorado, USA, 21-24

408 September 2008. Society of Petroleum Engineers.

409 Hatiboglu, C., Babadagli, T.: Diffusion mass transfer in miscible oil recovery: visual

410 experiments and simulation. Trans Poros Media. 74(2), 169-184 (2008)

411 Jamshidnezhad, M., Montazer-Rahmati, M., Sajjadian, V.A.: Theoretical and experimental

412 investigations of miscible displacement in fractured porous media. Trans Poros Media. 57, 59-

$413 \quad 73(2004)$

414 Jiang, T., Zeng, F., Jia, X., Gu, Y.: A new solvent-based enhanced heavy oil recovery method:

415 cyclic production with continuous solvent injection. Fuel. 115, 426-433 (2014)

416 Karimaie, H., Lindeberg, E.G.B., Torsaeter, O., Darvish, G.R.: Experimental investigation of

417 secondary and tertiary gas injection in fractured carbonate rock. In: EUROPEC/EAGE

418 Conference and Exhibition, London, UK, 11-14 June 2007. European Association of

419 Geoscientists \& Engineers.

420 Karimaie, H., Torsaeter, O.: Low IFT gas-oil gravity drainage in fractured carbonate porous

421 media. J. Pet. Sci. Eng. 70 (1-2), 67-73 (2010) 
422 Kahrobaei, S., Farajzadeh, R., Suicmez, V.S., Bruining, J.: Gravity-enhanced transfer between

423 fracture and matrix in solvent-based enhanced oil recovery. Ind. Eng. Chem. Res. 51 (44),

$424 \quad 14555-14565(2012)$

425 Lederer, E.L.: Viscosity of mixtures with and without diluents. In proceedings of the First

426 World Petroleum Congress, London: World Petroleum Council (1933)

427 Leyva-Gomez, H., Babadagli, T.: Hot solvent injection for heavy oil/bitumen recovery from

428 fractured reservoirs: an experimental approach to determine optimal application conditions.

429 Energy Fuels. 30 (4): 2780-2790 (2016)

430 Marle, C.M.: Multiphase flow in porous media. Gulf Publishing Company, Editions Technip,

$431 \quad$ Paris (1981)

432 Mattax, C.C., Kyte, J.R.: Imbibition oil recovery from fractured, water-drive reservoir, Water-

433 Drive Reservoir. SPE J. 2 (2), 177-184 (1962)

434 Mayorquin-Ruiz, J., Babadagli, T.: Low temperature air injection with solvents in heavy-oil

435 containing naturally fractured reservoirs: Effects of matrix-fracture properties and temperature

436 on recovery. Fuel. 179, 376-390 (2016)

437 Oliveira, M.F., Barillas, J.L.M., Mata Junior, T.V.: A parametric study of solvent injection as a

438 recovery method for heavy oil and bitumen reservoirs. In: Latin American and Caribbean

439 petroleum Engineering Conference, Colombia, 31 May-3 June 2009. Society of Petroleum

440 Engineers. 
441 Okazawa, T.: Impact of concentration dependence of diffusion coefficient on VAPEX drainage

442 rates. J. Can. Pet. Technol. 48 (2), 47-53 (2009). doi: http://dx.doi.org/10.2118/09-02-47

443 Pathak, V., Babadagli, T., Edmunds, N.: Experimental investigation of bitumen recovery from

444 fractured carbonates using hot solvents. J. Can. Pet. Technol. 52 (4), 289-295 (2013)

445 Penny, R., Moosa, R., Sahin, G., Hadhrahmi, F., Kok, A., Engen, G., van Ravesteijn, O.,

446 Rankin, K., Nguyen, B., van Dorp, J., Verlaan ,M., Castellanos-Diaz, O., Nguyen, Q.P.:

447 Solvent injection strategy for low-temperature production from fractured viscous oil reservoirs.

$448 \quad$ Energy Fuels. 28 (7), 4342-4354 (2014)

449 Pooladi-Darvish, M., Farouq Ali, S.M.: Steam heating of fractured formations containing heavy 450 oil: basic premises and a single-block analytical model. In: SPE Annual Technical Conference 451 and Exhibition, New Orleans, USA, 25-28 September 1994. Society of Petroleum Engineers.

452 Pooladi-Darvish, M., Firoozabadi, A.: Cocurrent and countercurrent imbibition in a water-wet 453 matrix block. SPE J. 5(1), 3-11 (2000)

454 Rahnema, H., Kharrat, R., Rostami, B.: Experimental and numerical study of vapor extraction 455 process (VAPEX) in heavy oil fractured reservoir. In: Canadian International Petroleum 456 Conference, Calgary, Canada, 17-19 June 2008. Society of Petroleum Engineers.

457 Rawnsley, K., Kharusi, B.: Steam injection in fractured carbonate reservoirs: starting a new 458 trend in EOR. In: International Petroleum Technology Conference, Doha, Qatar, 21-23

459 November 2005. doi: 10.2523/10727-MS. Society of Petroleum Engineers. 
460 Shu, W.R.: A viscosity correlation for mixtures of heavy oil, bitumen, and petroleum fractions.

$461 \quad$ SPE J. 24 (3), 277-282 (1984)

462 Saidi, A.M.: Reservoir engineering of fractured reservoirs: fundamentals and practical aspects.

463 Total, France (1987)

464 Torabi, F., Qazvini Firouz, A., Kavousi, A., Asghari, K.: Comparative evaluation of

465 immiscible, near miscible and miscible CO2 huff-n-puff to enhance oil recovery from a single

466 matrix-fracture system (experimental and simulation studies). Fuel. 93, 443-453 (2012)

467 Trivedi, J., Babadagli, T.: Efficiency of diffusion controlled miscible displacement in fractured 468 porous media. Trans Poros Media. 71(3), 379-394 (2008) 